Holtz, as quoted in the earlier part of my lecture, previous to my own practical experiments. For had $I$ read such opinions from such authorities I should probably have accepted them without putting them to practical test. As the matter stands I have done those things which they said I ought not to have done, and I have left undone those which they said I ought to have done, and by so doing I think you must freely admit that I have produced an electric generating machine of great power, and have placed in the hands of the physicist, for the purposes of public demonstration, or original research, an instrument more trustworthy than anything hitherto produced.

\section{NOTE ON THE TARPON OR SILVER KING (MEGALOPS THRISSOIDES).}

THE genus Megalops belongs to the family Clupeidæ, and, amongst other features, is characterized, according to Dr. Günther, ${ }^{1}$ by an oblong compressed body, the presence of a narrow osseous lamella attached to the mandibular symphysis and lying between the halves of the mandible. Further, the latter is prominent, the intermaxillary short, the maxillary forming the lateral part of the mouth. There are bands of villiform teeth on the jaws, vomer, palatines, pterygoid, tongue, and base of skull.

The interest in the species above-mentioned has been considerably increased of late by the fact that the huge fish (between 5 and 6 feet in length, and weighing from 90 to 150 pounds) can be caught by rod and line, and I am much indebted to Lady Playfair for giving me all the information she had obtained on the subject through her father and Mr. W. G. Russell of Boston, United States.

The tarpon (Megalops thrissoides) frequents the Atlantic shores of North America, and is especially found "on the western or Gulf coast of Southern Florida, haunting the shallow bays and creeks inside the bars and keys which stretch along that coast; and the fishes are supposed to enter by the passes from the outer Gulf. 2

"In shape the tarpon somewhat resembles the salmon, but, as hecomes one of the herring tribe, it is deeper and less rounded, and the head is larger, the scales (cycloid) are thick and large, more than an inch in diameter" (a fine scale sent by Lady Playfair measures $2 \frac{1}{4}$ inches both in antero-posterior and transverse diameter), "and the exposed portion is of a bright silvery hue, indeed it looks as if it had been dipped in silver and burnished: hence the name 'silver king.' I have seen specimens weighing from 50 to 137 pounds, and have heard of none above 150 pounds.

"The tarpon has always been upon the Gulf coast, but was formerly captured, as the sword-fish is, by the harpoon. In 1885, however, a Mr. Wood undertook successfully to secure the fish by rod and reel. . . . About 150 have been caught in this manner during the seasons 1885 and 1886 , the time being in March and April, perhaps a little earlier in a warm season : after April it is too hot for fishing.

"The fish is caught on the edge of the channels in $\mathrm{x} 5$ to 25 feet of water with a bait of (half a) mullet. The rod should be very stiff, not more than 9 feet in length, such as is used for large sea-bass, and the line strong, but fine enough to carry 200 to 250 yards on the reel, which must therefore be large and heavy. A snood or gauging of about 3 feet of cor-line, copperwire, or chain, should be fixed to the hook ${ }^{3}$ as the dental apparatus of the fish efficiently combines a file and shears, with which even a double cod-line may be frayed or worn off, or severed without a sensible strain.

"The tarpon takes the bait lying on the bottom, and moves off, swallowing it, until he is struck, and the moment he feels the hook he is cut of the water, perhaps 3 or 6 feet in the air, shaking his head fiercely -as does the black bass-to disengage the hook, and then begins such a fight as, I believe, no other game fish ever shows. It frequently leaps with a clean breach twenty times before the game is over, and so close that it occasionally sends a douche over the boatmen; while in one instance a large one made a run of 100 yards, the whole of which was a succession of frantic leaps and plunges, leaving a wake like that of a steamer. The same fish towed my boat, with three men in it,

I "Introduction to Fishes," pp 661-62.

2 Extracted from a description (from persona! observation) by Mr. W. G. Russell, of Boston.

${ }^{3}$ Described elsewhere as "an O'Shaughnessy knobbed ro-o hook." about two miles, and, after more than an hour's hard fight, ended by three huge leaps out of the water amongst some margrovetrees, the oysters on the roots of which cut my line, so that we parted company after a cluse and protracted intimacy."

There is little doubt, from the foregoing remarks, that the solendid sport of tarpon-fishing must make it most fascinating. In April 1887, indeed, a single rod caught nine fish in eleven days, two of them weighing respectively $\mathrm{I}_{5} \mathrm{I}$ and $\mathrm{I} 49$ pounds, and in length 6 feet 4 inches, and 6 feet 5 inches. These were taken at Punta Rassa on the western coast of Florida, the total weight of the catch being 1042 pounds, or an average of about 1 I 6 pounds for each. The tarpon, like others of its tribe, has the advantage also of being good food.

W. C. McIntosh.

\section{SCIENTIFIC SERIALS.}

Bulletins de la Société D'Anthropologie de Paris, tome dixième, 4e fascicule, 1887.- This closing number for the last year enumerates the various presentations made to the Society since the previous publication of the Bulletins. Among the recent communications attention is due to $M$. Boban's report of the interesting collection of North American flint instruments presented to the Society by the Smithsonian Institution. They appear to be almost identical with those existing in Europe, and belonging to the Stone Age. $-M$. Verneau, on presenting various stone instruments from the Canary Isles, drew attention to their rude forms, due, he believes, to the relatively brittle character of the basalt and obsidian from which they were cut. The few specimens of polished stone belong only to Gomère and Canary Proper, and are, therefore, conjectured to have been introduced by some of the numerous North African invaders who landed on those islands.-M. André Sanson's paper on experimental craniology in reference specially to domestic animals, which he considers under two cephalic types only, viz. the dolicocephalic and the brachycephalic, is directed against the systems of craniometry and anthropometry at present in vogue. M. Fauvelle took a leading part in the discussion to which the paper gave rise, and gave his views in regard to the value of the cephalic index, which he considered to have been greatly overestimated by Broca and his followers. These remarks, and the refutation of Broca by M. Topinard, form, with M. Sanson's paper, a complete exposition of the various views maintained in different provinces of anthropological science in France.-Report on the various papers presented by competitors for the Godard Prize in I887, by M. Moudière. - On aphasia and its history since the original observations of Broca, by M. M. Duval. - On the distinctive characteristics of the human brain considered from a morphological point of view, by M. le Dr. S. Pozzi.-On a case of supernumerary digits on the cubital margin of each hand, by Dr. Béranger.-On the morphological variability of the muscles under the influence of functional variations, by Mme. Clémence Royer.- - On the abnormal elongation of the cuboides, accompanied by the pressure of a round pronator in a horse, by M. E. Cuyer. - On the tumulus of Kerlescan at Carnac, by M. Gaillard. The remains of this interesting monument, with its double dolmens similar to the covered allées, known as "Hunebeds" in Holland, were first described in 1860 , since which time they have suffered so much from neglect and wanton injury that $M$. Gaillard is making a strong appeal to the Government for their protection. - Note on the tumuli of a covered gallery, examined in 1887 , near Montigny l'Engrain (Aisne), by M. Vauville, and report of the crania found there, and referred to the Furfooz men of the dolmen age, by Dr. Verneau. The preponderating character of these crania was their length and straightness. Several bore marks of cicatrised wounds.-On a Quaternary equidean, similar to the kertag of Kirghis, described by M. Poliakoff under the the name of Equzes Przeivalskii. The description of the kertag with its short and straight mane, its relatively large head and inferior height, corresponds remarkably well with the numerous representations of the Quaternary equidean found in different parts of Western Europe among the varied debris that mark the site of primæval settlements. In the Magdelian carvings found in the cavern at Arudy among mammoth bones, special prominence is given to the thin, rat like character of the tail of the animal, a feature that is very marked in the kertag, which appears to be the nearest living representative of the horse of the Quaternary age. 
Bulletin de l'Acaldemie Koyale de Belsique, May. - On the new elements of the orbit of Eucharis, by $L$. de Ball. Continuing his researches on the elements of this planet (181), the author here establishes two new normal positions by means of the observations made in 1886 and 1887 . He also revises the positions of the comparison stars, and resumes the calculation of the perturbations caused by Jupiter, Saturn, and Mars, utilizing for the last named the results of Asaph Hall's observations on the satellites. - Contribution to the study of pulsation in the lower animal organisms, by Dr. De Bruyne. The results are given of the author's studies on the pulsating function of an encysted Protoznon obtained in abundance by culture, but of not yet determined family. From his minute observations on the formation, development, and action of the vesicle endowed with rhythmical motion, he concludes that this organ has no communication with the periphery, and has nothing to do with the digestive function, as is commonly supposed, but is a true organ of respiration and circulation, a heart and lung combined.

\section{SOCIETIES AND ACADEMIES. LONDON.}

Royal Society, May 3r.- "The Conditions of the Evolution of Gases from Homogeneous Liquids." By V. H. Veley, M.A., University College, Oxford.

In Part I. an account is given of the effect of finely divided particles on the rate of evolution of gases resulting from chemical changes; in Part II. the phenomenon of initial acceleration, as also the effect of variation of pressure on the evolution of gases, is discussed; in Part III. the case of the decomposition of formic acid into carbonic oxide and waier is investiuated under constant conditions, other than those of the mass of reacting substances and of temperature.

Part 1. - It is found that the addition of finely rlivided chemically inert particles increases the rate of evolution of gases from liquids in which they are being formed. The effect of these particles on the following chemical changes is investigated (i.) the decomposition of formic acid yielding carbonic oxide ; (ii.) the decomposition of ammonium nitrite in aqueous solution yielding nitrogen; (iii.) the reduction of nitric acid into nitric oxide by means of ferrous sulphate; (iv.) the decomposition of ammonium nitrate in a state of fusion producing nitrous oxide ; and (v.) the decomposition of potassium chlorate in a state of fusion producing oxygen. 'The finely divided substances used are pumice, silica, graphite, precipitated barium sulphate and glass-dust.

Part II. - It is observed that, conditions of temperature remaining the same, the rate of evolution of a gas from a liquid is at first slow, then gradually increases until it reaches a maximum, and for some time constant, rate. From this point the rate decreases proportionally to the diminution of mass. This is observed in the cases of decomposition of formic acid, potassium ferrocyanide, and of oxalic acid by concentrated sulphuric acid, and in that of ammonium nitrate. It has previously been ob. served in the case of the decomposition of ammonium nitrite in aqueous solution. The same phenomenon repeats itself when the temperature is temporarily lowered and then raised to its former point, and also to a more marked degree when, temperature remaining the same, the superincumbent pressure is suddenly increased.

The reduction of pressure from one to a fraction of an atmosphere produces no permanent effect on the rate of evolution of a gis from a liquid; a decrease of pressure, however, produces temporarily an increase in the rate, and an increase of pressure conversely produces temporarily a decrease in the rate.

Part III. - The case of the decomposition of formic acid into carbonic oxide and water by diluted sulphuric acid is studied with the aid of an apparatus by means of which the temperature is kept constant within one-twentieth of a degree. It is shown that the rate of evolution of carbonic oxide is expressible by the following equation-

$$
\log (\tau+t)+\log r=\log c
$$

in which $\tau$ is the time from the commencement of the observa. tions; $t$ is the interval of time from the moment of commencement, and that at which, conditions remaining the same, the interval of time required for unit change would have been nil; $r$ is the mass at the end of each observation, and $c$ is a constant.
The results calculated by this hypothesis agree with those ob. served, whether the interval of time required for unit change is 30 or 960 minutes. The curve expressing the rate of chemical change in terms of mass is thus hyperbolic and illustrative of the law-

$$
\frac{d r}{d \tau}=-\frac{r^{2}}{c},
$$

which expresses the rate at which equivalent masses act upon one another $; \mathrm{I} / \mathrm{c}$ in each experiment is the amount of each unit mass which reacts with the other per unit of time, when a unit mass of each substance is present. Since, then, equivalent masses take part in the change, it is reasonable to suppose that at first an anhydride of formic acid is produced, which is subsequently decomposed into carbonic oxide and water.

The change may thus be compared to the production of ethyl formate from formic acid and alcohol, with which it shows several points of analogy.

June 14. - "The Electric Organ of the Skate. Structure and Development of the Electric Organ of Raia ratiata." By J. C. Ewart, M.D., Regius Professor of Natural History, University of Edinburgh. Communicated by Prof. J. Burdon Sanderson, F.R.S.

The first part of this paper is chiefly devoted to a comparison of the electric organs of Raia radiata, Raia batis, and Raia circularis. It is shown that the organ in the species ratiata differ in many respects from the organ in the tws other species, and that an exhaustive study of its structure and development is likely to throw considerable light on the nature of electric organs generally, and also on the structure of the motor plates of muscles. While Raia batis may reach a length of over $180 \mathrm{~cm}$., Raia radiata seldom measures more than $45 \mathrm{~cm}$. from tip to tip, and is thus only about balf the size of a large Raia circularis. In Raia radiata the electric organ is absolutely and relatively extremely small. In Raia batis the electric organ may be $60 \mathrm{~cm}$. in length and $7 \mathrm{~cm}$. in circumference at the centre, and extend from the shin to the vertebral column, but in an adult Raia radiata the organ is seldom over $13 \mathrm{~cm}$. in length and $8 \mathrm{~mm}$. in circumference, and the posterior two-thirds is confined to a narrow cleft between the skin and the great lateral muscles of the tail. Further, the organ of Raia raliata consists of minute shallow cups, which only remotely resemble the large well formed electric cups of Raia circularis. In the latter species the various layers of the electric cup are readily comparable to the more important layers of the electric disk of Raia batis, but in Raia radiata the electric cup is little more than a muscular fibre, with one end expanded and slightly excavated to support a greatly enlarged motor plate, in which terminate numerous nerve-fibres. The striated layer of Raia batis and circularis, which consists of characteristic lamellx, having an extremely complex arrangement, is entirely absent from Kaia radiata, the electric layer is indistinct, and instead of a thick richly nucleated cortex, the cup is merely invested by a slightly thickened sarcolemma. Further, the tissue forming the shallow, thick-walled cup, both in its appearance and consistency, closely resembles an ordinary muscular fibre, while the long stem usually remains distinctly striated to its termination.

In the second part of the paper an account is given of the development of the electric cups of liaia ratiata. It is shown that the rate of development compared with Raia circularis, but more especially with Raia batis, is extremely slow. The young radiata is nearly double the size of the batis embryo before the muscular fibres reach the "club" stage, and the long nearly uniform clubs, instead of at once developing into rudimentary cups as is the case in batis, assume the form of large Indian clubs. When the young skate reaches a length of about $35 \mathrm{~cm}$., the long secondary clubs begin to expand anteriorly, and this expansion continues until a fairly well-moulded cup mounted on a long delicate stem is produced. But the process of conversion is scarcely completed when the skate has reached a length of 40 $\mathrm{cm}$., i.e. when it has nearly reached it: full size, for in the species radiata a length of $50 \mathrm{~cm}$. is seldom if ever attained.

The cup-stage having been eventually reached, the stem, which for a time may still increase in length, is often compressed by two or more cups being closely applied together, and part of the rim of the cup may be slightly everted or projected forwards, but even in the largest specimens of Rata ratiata examined there was never any indication of retrogressive changes.

The small size of the electric organ, together with the shallowness of the minute cups of which it consists, seems at furst to indicate that in Raia radiata we have an electric organ in the 